\title{
ENHANCING ASPHALT RHEOLOGICAL BEHAVIOR AND AGING SUSCEPTIBILITY USING BIO-CHAR AND NANO-CLAY
}

\author{
Renaldo C. Walters, Elham H. Fini and Taher Abu-Lebdeh \\ Department of Civil, Architectural and Environmental Engineering, \\ North Carolina A and T State University, Greensboro, NC 27411, USA
}

Received 2014-01-31; Revised 2014-02-13; Accepted 2014-03-24

\begin{abstract}
The life expectancy of Asphalt Binder (AB) has been negatively impacted by the harsh bombardment of UV rays. UV rays cause asphalt to oxidize faster, which results in deterioration of asphalt rheological characteristics that can lead to pavement distresses. This study investigates the impact of bio-char and nanoclay of asphalt rheological properties. Two nano scale materials were used for this study were nano-clay and bio-char. Nano-clay (Cloisite 30B) is a naturally occurring inorganic mineral. Bio-char is the waste product from bio-binder production. Bio-binder is produced from swine manure using a thermochemical conversion process. This process is then followed by a filtration procedure where the bio-char is produced. Chemical and physical properties of bio-char showed a significant presence of carbon which could in turn enhance asphalt flow properties and reduce the rate of asphalt oxidation. In this study several mixtures are designed and evaluated using Rotational Viscometer testing (RV) and X-Ray Diffraction (XRD). Nano-clay is blended at 2 and $4 \%$ by weight, with and without bio-binder ( $5 \%$ by weight of dry mass). Bio-char is grinded to nano scale and added to the virgin asphalt binder (PG 64-22) at 2, 5 and $10 \%$ by weight. The study results showed that introduction of nano-clay could be effective in reducing temperature susceptibility of asphalt binder.
\end{abstract}

Keywords: Oxidation, Nano-Particle, Bio-Modification, Rheological Properties, Aging Susceptibility

\section{INTRODUCTION}

The physiochemical mechanisms of asphalt oxidative aging and changes in the performance-related properties of asphalt have been the subject of numerous research investigations and much speculation for many decades. In this study two nano materials: Nano-clay and bio-char are blended separately with Asphalt Binder (AB) and BioModified Binder (BMB) to reduce enhance asphalt properties and reduce oxidation aging. The selected $\mathrm{AB}$ was PG 64-22, which is commonly used in North Carolina and $\mathrm{BMB}$ was a bio-asphalt produced at NC A\&T farm mainly from swine manure (Fini et al., 2011a). Due to increasing concerns about the service life of asphalt binders, this study strives to decrease the rate of asphalt oxidation, which is known as one of the main causes of pavement distresses. This in turn will enhance rheological behavior of asphalt and extend pavement service life by reducing asphalt aging susceptibility.

Asphalt binders are most commonly characterized by their physical properties. Asphalt binder's physiochemical properties determine how it will perform as a constituent in Asphalt Concrete (AC) pavement. Although asphalt binder viscosity grading is still common, new binder tests and specifications have been developed to more accurately characterize asphalt binders for use in AC pavements (ASTM, 2013). These tests and specifications are specifically designed to

North Carolina A and T State University, 1601 E. Market Street, Greensboro, NC 27411,

USA Tel: (336) 285-3676 Fax: (336) 334-7126 
address AC pavement performance parameters such as rutting, fatigue cracking and thermal cracking (ASTM, 2013). Performance Graded (PG) asphalt binders are selected to meet expected climatic conditions as well as aging considerations with a certain level of reliability. Therefore, the PG system uses a common set of tests to measure physical properties of the binder that can be directly related to field performance of the pavement at extreme temperatures (CDT, 2013). For example, a binder identified as PG 64-10 must meet performance criteria at an average 7-day maximum pavement design temperature of $64^{\circ} \mathrm{C}$ and also at a minimum pavement design temperature of $-10^{\circ} \mathrm{C}(\mathrm{CDT}, 2013)$. In addition to asphalt binder, bio-binder produced from swine manure has been used in this study to create bio-modified asphalt. It should be noted that application of bio-binder enhances pavement sustainability while facilitating manure management. Swine manure contributes to environmental pollution and greenhouse gas emission, this study introduces a hybrid approach, which uses swine manure to produce a sustainable alternative for petroleum-based asphalt while investigating effects of various nano particles in reducing oxidative aging. According to the USDA, more than 335 million tons of manure is produced annually in the U.S with 40.2 million tons being from swine. North Carolina alone (which ranks second in hog production after Iowa) produces 5.3 million tons of swine manure every year USDA, 2005. Currently, a very small portion (approximately 5\%) of U.S cropland is fertilized with livestock manure (MacDonald and McBride, 2009); the remaining manure is mainly transported and disposed of by storing it in lagoons. This process has several significantly negative environmental impacts, particularly with respect to surface water, groundwater quality and air quality due to odors and gaseous emission from large-sale swine production operations (Ocfemia et al., 2005; Xiu et al., 2011). Four gases of immediate concern are Hydrogen Sulfide $\left(\mathrm{H}_{2} \mathrm{~S}\right)$, Carbon Dioxide $\left(\mathrm{CO}_{2}\right)$, Ammonia $\left(\mathrm{NH}_{3}\right)$ and Methane $\left(\mathrm{CH}_{4}\right)$ which, at elevated exposure levels, generate health issues ranging from mild irritation to death for both animals and humans (Thu et al., 1997). Additionally, gases such as Dinitrogen Oxide $\left(\mathrm{N}_{2} \mathrm{O}\right)$, Methane $\left(\mathrm{CH}_{4}\right)$ and Carbon Dioxide $\left(\mathrm{CO}_{2}\right)$ are associated with greenhouse effects (Jarecki et al., 2008).

In this study to enhance the flow and dispersion as well as reduce U.V. aging, bio-char was added to asphalt binder. Bio-char (biologically derived charcoal) is the waste product from a hydrothermal process used to produce bio-binder from swine manure. This material is heavily used in the farming industry as fertilizer. Bio-char has the potential to increase conventional agricultural productivity and enhance the ability of farmers to participate in carbon markets beyond the traditional approach by directly applying carbon to soil (McHenry, 2009). Applying bio-char to the soil replaces carbon, nitrogen and most of the plant nutrients that are removed from the soil with the biomass. The carbon content in bio-char is highly stable in soil environments and may be sequestered for thousands of years (Mullen et al., 2010). Producing bio-char from farm or forestry waste provides an impressive list of potential co-benefits, including the generation of renewable electricity, liquid biofuels, gas biofuels, activated carbon, eucalyptus oil, a large amount of heat or low-pressure steam as well as potential of net withdrawal of carbon dioxide from the atmosphere (McHenry, 2009). The optimum bio-char production temperature in terms of carbon recovery, CEC and surface area is $500^{\circ} \mathrm{C}$. Biochar produced under $400^{\circ} \mathrm{C}$ has a low surface area and may not be useful as an agricultural soil improver (Lehmann, 2007). To enhance aging resistance of asphalt nano-clay was added to asphalt binder. Nanoclay, which is from Southern Clay Products Inc., has been used commonly in the polymer industry to achieve increased mechanical and physical properties such as stiffness, toughness, strength and thermal stability (Lee et al., 2005). The primary use of nano particles as modifiers in asphalt binders has been to enhance rutting and cracking resistance (You et al., 2011; Goh et al., 2011; Amirkhanian et al., 2010). In the asphalt industry many organic and non-organic modifiers have been used with the goal of lowering bitumen viscosity, reducing carbon emissions, lowering energy consumption and improving bitumen workability (Rubio et al., 2012). Traditionally, the purpose of applying modifiers has been mainly to extend the asphalt's high and low temperature performance grade or to enhance aging resistance of asphalt binder. In addition, the environmental concerns of the asphalt industry led to the promotion of green asphalt technologies. These new technologies can lead to a reduction in the carbon footprint of pavements by the use of Warm Mix Asphalt (WMA), Half-Warm Mix Asphalt (HWMA) and Cold Mix Asphalt (CMA) which reduce fuel consumption and $\mathrm{CO}_{2}$ production. To enhance rheological properties of asphalt while improving its aging resistance, this study investigate effectiveness of application of biochar and nano-clay to asphalt binder. 


\section{PROBLEM STATEMENT}

The research study in this study focuses on evaluating the effects of nano-particles on the rheological properties and aging susceptibility of asphalt binder and biomodified asphalt binder with different percentages of two nano materials (nano-clay and bio-char) to undertake various tests. These tests were conducted to determine the viscosity, crystalline structure, chemical bonds in biomodified asphalt and inter layer spacing of nano clay. The specimens being tested contain bio-char $(2,5$ and $10 \%$ by weight) and nano-clay ( 2 and $4 \%$ by weight).

\section{EXPERIMENTAL METHOD}

The research hypothesis is that the inclusion of nano materials in asphalt binder enhances asphalt binder's rheological properties and reduces its aging susceptibility. To test this hypothesis the following research approach was taken to evaluate the rheological characteristics, crystalline structure, inter layer spacing and chemical bonds in control asphalts and those modified with various percentages of nano-clay and bio-char.

\subsection{Rotational Viscosity (RV) Test}

The Rotational Viscometer (RV) test was conducted using the Brookfield rotational viscometer and according to the ASTMD 4402 standard specification. Test results were used to compare dynamic shear viscosity among various modifications in this study. Tests were conducted at 120,135 and $150^{\circ} \mathrm{C}$ temperatures.

\subsection{X-Ray Diffraction Test}

X-Ray diffraction test was conducted using XPERTPRO Diffractometer system. This test is used to depict a materials polycrystalline structure. The main use of powder diffraction is to identify components in a sample by search/match procedure. Data was collected between the angles of 4 and $60^{\circ} 2 \mathrm{Th}$ for a two hour period for each sample. For all samples including nano-clay, 0.02 RAD soller slits were used on both incident and receiving side. For bio-char samples, 0.04 RAD soller slits were used which increase the intensity of the X-Ray beam. Purpose of a soller slit is to take a line source of radiation and slice it into smaller parallel beams. This reduces axial divergence of the beam.

\subsection{Temperature Susceptibility}

Temperature Susceptibility is a measure of how fast the properties of binder changes with temperature (Claudy and Martin 1998); therefore, if a sample of binder has a high susceptibility to temperature, its viscosity changes rapidly as the temperature changes. Asphalt binders with high temperature susceptibility are not desirable as they are more prone to thermal and U.V. oxidation (Firoozifar and Foroutan, 2011). Therefore, it is important to numerically quantify this rheological property of a binder. Following equation has been commonly used to calculate the Viscosity-Temperature Susceptibility (VTS) (Rasmussen et al., 2002) Equation 1:

$\mathrm{VTS}=\frac{\log \left(\log \left(\left(\eta 2 \mathrm{~T}_{2}\right)\right)-\log \left(\log \left(\eta 1 \mathrm{~T}_{1}\right)\right)\right.}{\log \left(\mathrm{T}_{2}\right)-\log \left(\mathrm{T}_{1}\right)}$

Where:

$\mathrm{T}_{1}=$ The temperature at point one $\left({ }^{\circ} \mathrm{C}\right)$,

$\mathrm{T}_{2}=$ The temperature at point two $\left({ }^{\circ} \mathrm{C}\right)$,

$\eta_{1}=$ Viscosity at point one $(\mathrm{cP})$ and

$\eta_{2}=$ Viscosity at point two $(\mathrm{cP})$

The magnitude of the VTS is directly proportional to the temperature susceptibility of the binder (Rasmussen et al., 2002). The dimension of the VTS is directly proportional to the temperature susceptibility of the asphalt binder.

\subsection{Shear Susceptibility}

Shear Susceptibility is defined as the rate of change in viscosity with the shear rate (Roberts et al., 1996). The shear susceptibility or also known as the shear index is determined by calculating the slope of the line formed by a $\log$ of rotational speed versus the $\log$ viscosity graph using Equation 2.

$\mathrm{SS}=\frac{\log (\text { Viscosity })}{\log (\text { speed })}$

Where:

Viscosity $=$ Measure of deformation by shear or tensile stress

Speed $=$ Rate at which shear is applied to material

Prior studies showed that binder with relatively small shear susceptibility (low gains in shear susceptibility relative to the increase in viscosity) results in better overall pavement performance (Roberts et al., 1996).

\section{MATERIAL CHARACTERIZATTION}

\subsection{Asphalt Binder}

The control asphalt (PG 64-22) binder which was obtained from a local asphalt supplier SBI, 2013 was 
utilized in the design of the modified asphalt studied in this study. PG 64-22 has a mixing temperature range of $152-159^{\circ} \mathrm{C} \quad\left(306-318^{\circ} \mathrm{F}\right)$. Compaction temperatures of this asphalt range from $140-146^{\circ} \mathrm{C}$ $\left(284-294^{\circ} \mathrm{F}\right)$ while its storage temperature ranges from $135-177^{\circ} \mathrm{C}\left(275-350^{\circ} \mathrm{F}\right)$.

\subsection{Bio-Binder}

The bio-binder was produced from the thermochemcial conversion of swine manure to bio-oil followed by distillation and filtration (Fini et al., $2011 b$ ). In this method animal waste is charged in the reactor. Nitrogen gas is used as a processing gas to purge the residual air in the reactor three times. The reactor is heated up to the setting temperature, which is maintained at a constant level for a specific time. After the reaction is completed, the reactor is rapidly cooled down to room temperature by using a recycled ice-water cooling coil. The gas is then released from the autoclave reducing the pressure in the autoclave to atmospheric pressure. The sticky residue is then separated from the aqueous solutions by filtration under vacuum to acquire bio-binder for further testing and characterization. The parameters for the conversion include a temperature of $305^{\circ} \mathrm{C}$, pressure of $10.3 \mathrm{MPa}$ and a residual time of $80 \mathrm{~min}$. Efficiency for the conversion was about $70 \%$ (based on dry mass). During the distillation, bio-oil's viscosity was measured every $10 \mathrm{~min}$ to obtain bio-binder (residue) with a specified viscosity. The oil was further processed using vacuum distillation and filtration.

\subsection{Bio-Char}

Bio-char used in this study was the waste product of a thermochemical process used to convert swine manure into bio-oil. Bio-char is available after the filtration process. A vacuum pump is placed in a confined environment to prevent the spilling of the bio-oil. One end of a transparent hose is connected to vacuum end of the pump and the other end of the transparent hose is connected to a glass beaker. A rubber stopper is placed in the top of the glass beaker. A sieve is connected to a funnel which is then placed inside the rubber stopper. A sheet of filter paper is placed inside the sieve. Bio-oil is poured over the filter paper. Vacuum pump is then switched on. When all the liquid has been pulled through the filter paper and sieved into the glass beaker, a very fine solid residue (bio-char) remains on top of the filter.

\subsection{Nano-Clay (Cloisite 30B)}

Cloisite 30B is an alkyl quaternary ammonium salt bentonite. It is an additive that is off white in color and is used to improve various physical properties. Its moisture content is less than $3 \%$ and its particle size is approximately $10 \mu \mathrm{m}$, with density of $1.98 \mathrm{~g} \mathrm{cc}^{-1}$ and a d-spacing of $1.85 \mathrm{~nm} / 18.5 \AA$. Nano-clays are layered silicates that are found naturally and hence they are environmentally safe, economical and sustainable. One of the most frequently used layered silicates is Montmorillonite (MMT), which has a 2:1 layered structure with two silica tetrahedron layers sandwiching an alumina octahedron layer. These three layers together form one clay sheet that has a thickness of $0.96 \mathrm{~nm}$, thus the individual clay sheets are classified as "nano material," although the lateral dimensions of the individual clay sheet can vary from $100 \mathrm{~nm}$ to a few microns.

\subsection{Specimen Preparation}

PG 64-22 was placed in a bench top oven at $200^{\circ} \mathrm{C}$ for $30 \mathrm{~min}$. to reach a homogeneous liquid phase. Then it was blended with the selected modifier using a shear mixer for $20 \mathrm{~min}$ at 700rpm. The experimental design involves nine different modified asphalts as shown in Table 1 below.

Table 1. Experimental mixture design

\begin{tabular}{lcccc}
\hline & Control (PG 64-22) (\%) & Bio-binder (\%) & Bio-Char (\%) & Nano-Clay (\%) \\
\hline Sample 1 & 93 & 5 & & 2 \\
Sample 2 & 91 & 5 & & 4 \\
Sample 3 & 98 & & & 2 \\
Sample 4 & 96 & 98 & & 4 \\
Sample 5 & 0 & 96 & 2 & 4 \\
Sample 6 & 0 & & 5 & \\
Sample 7 & 98 & & 10 & \\
Sample 8 & 95 & & & \\
Sample 9 & 90 & & & \\
\hline
\end{tabular}




\section{RESULTS AND ANALYSIS}

The experimental design was conducted to characterize rheological properties of modified and nonmodified asphalt binder. The experimental tests were conducted using a Brookfield rotational viscometer (DVIII-Ultra). For each specimen, test was run in three replicates. Following combinations were tested:

- $\quad$ Bio-char and virgin binder (PG 64-22)

- Nano-clay and virgin binder (PG 64-22) with and without bio-binder

\subsection{Rheological Characterization}

To conduct the experiment Brookfield Rotational Viscometer (RV) was used following the ASTM D4402 test procedure (ASTM, 2013) at different temperatures and shear rates. The influence of the nano particle additive bio-char temperature and shear rate on viscosity was investigated. Figures $1 \mathbf{a}$ and $\mathbf{1 b}$ shows that the viscosity reduces with the increase in temperature for different concentrations of additive regardless of shearing rate. It can be seen at specific temperature as the percentage of additive increases so does the viscosity.

\subsection{Viscosity Temperature Susceptibility}

Figure $\mathbf{2 a}$ and $\mathbf{4 b}$ are plots of viscosity versus temperature for bio-char modified asphalt (2 and 5\% nano-clay asphalt ( 2 and $4 \%$ nano-clay). It can be observed that out of the three mixtures in Fig. 2a, $10 \%$

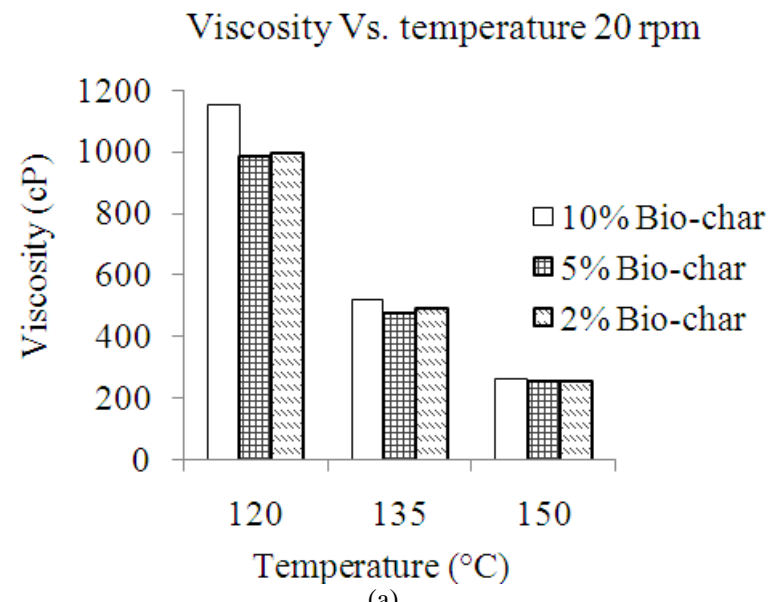

bio-char mixture has the highest temperature susceptibility. This result was true for all speeds evaluated for bio-char modified asphalt. It can be further seen that the temperature susceptibility for $2 \%$ bio-char and $5 \%$ bio-char additive are relatively close. Figure $\mathbf{2 b}$ shows that as the temperature increases, the temperature susceptibility decreases for each mixture. It can be observed that out of the three mixtures in Fig. 2b, $4 \%$ nano-clay mixture has the highest temperature susceptibility followed by $2 \%$ nano-clay mixture.

\subsection{Shear Susceptibility}

The shear susceptibility is illustrated in Fig. 3a and b at two different temperatures. From the analysis of Fig. 3a and b, when bio-char is added to asphalt binder, the viscosity decreases as the shear rate increases.

Figure 3b shows a plot of shear susceptibility of biochar mixed with PG $64-22$ at a temperature of $150^{\circ} \mathrm{C}$. The results at this temperature are consistent and the shear susceptibility decreases as the shear rate increases.

\subsection{Rotational Viscosity}

As shown in Fig. 4, the increase of the bio-char percentage from 2 to $5 \%$ leads to $5.4 \%$ increase in viscosity. Furthermore by introducing $10 \%$ bio-char the viscosity increases by $13 \%$ when compared to $2 \%$ bio-char mixture.

From the rotational viscosity results shown in Fig. 5 it is evident that with the addition of $2 \%$ nano-clay to control binder, the viscosity increases by an average of $22 \%$.

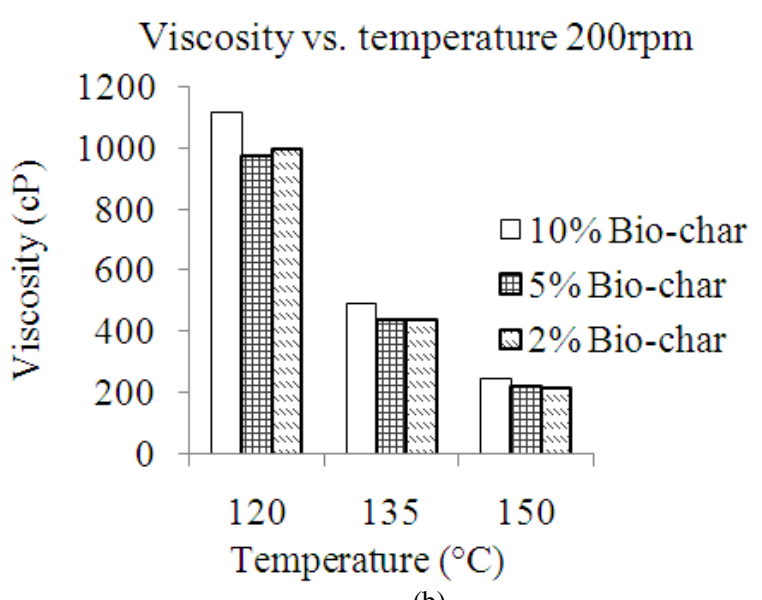

(b)

Fig. 1. (a) Viscosity Vs. Temperature for 2, 5 and $10 \%$ bio-char with PG 64-22 at 20 rpm, (b) Viscosity Vs. Temperature for 2, 5 and $10 \%$ bio-char with PG 64-22 at $200 \mathrm{rpm}$ 


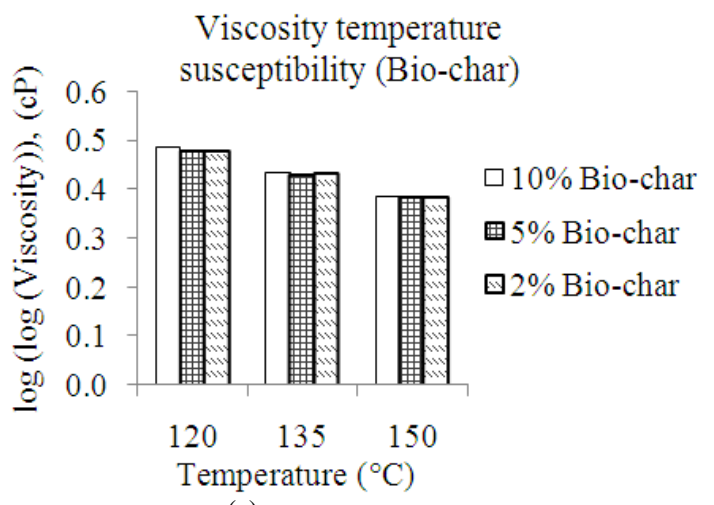

(a)

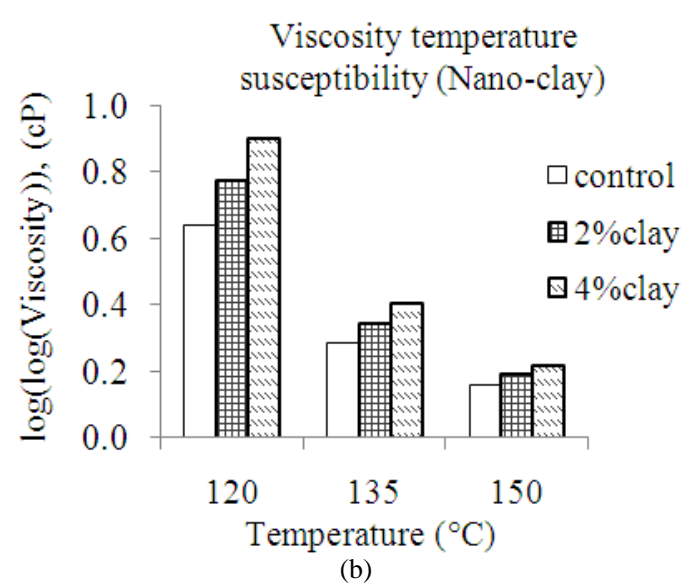

(b)

Fig. 2. (a) Viscosity temperature susceptibility for 2, 5 and $10 \%$ bio-char with PG 64-22, (b) Viscosity temperature susceptibility for control, 2 and $4 \%$ nano-clay

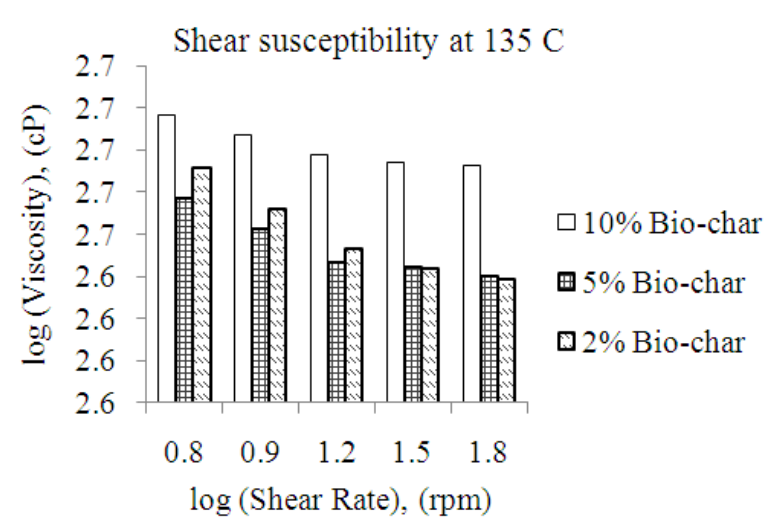

(a)

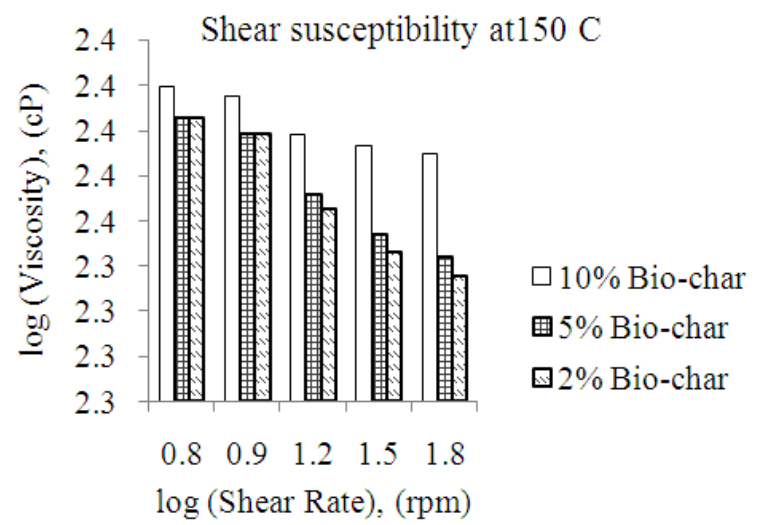

(b)

Fig. 3. (a) Shear susceptibility for 2,5 and $10 \%$ bio-char added to PG $64-22$ at $135^{\circ} \mathrm{C}$, (b) Shear susceptibility for 2,5 and $10 \%$ biochar added to PG $64-22$ at $150^{\circ} \mathrm{C}$

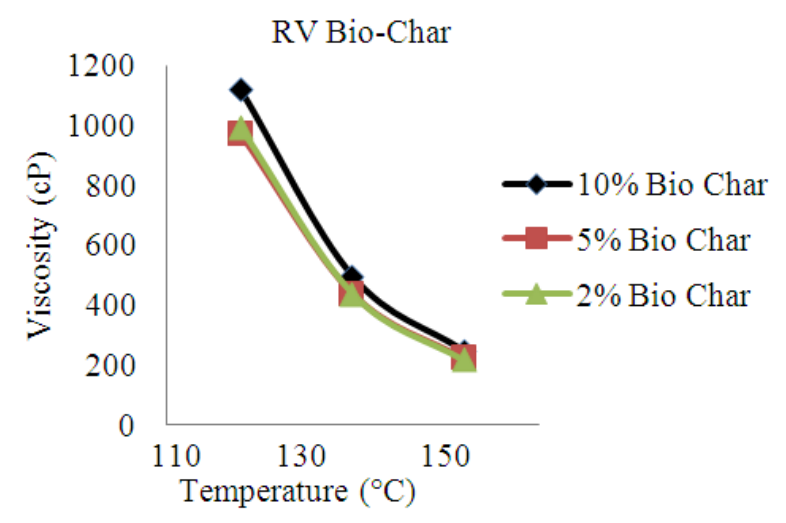

Fig. 4. Rotational Viscosity before aging of virgin asphalt binder (PG 64-22). Virgin asphalt binder and bio-char composites at different temperatures
However, introduction of $4 \%$ nano-clay increases the viscosity by $36 \%$ within the temperature range of 120 to $190^{\circ} \mathrm{C}$. It was also observed that addition of bio-binder to control binder (PG 64-22) leads to decrease of the viscosity by an average of $16 \%$; however when 2 and $4 \%$ nano-clay was added to the bio-modified binder, the viscosity increased by an average of 13 and 57\%, respectively.

\subsection{X-Ray Diffraction Test}

The exfoliation of nano particles in asphalt binders was examined at nano scale level using XRD techniques. The XRD is used to provide a quantitative analysis of the interlayer spacing and it provides a way to determine the extent of exfoliation of the nano-clay in the binder. In the XRD technique, Bragg's law of diffraction is used to measure d-spacing between nano-clay sheets. 


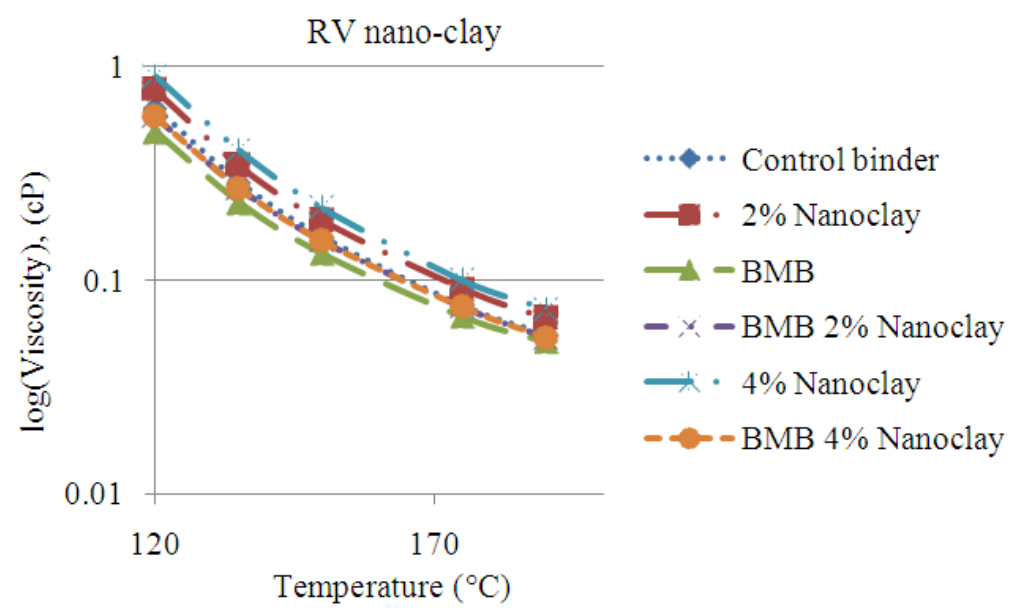

Fig. 5. Rotational Viscosity before aging for PG 64-22, Bio-modified binder, and Nano-clay

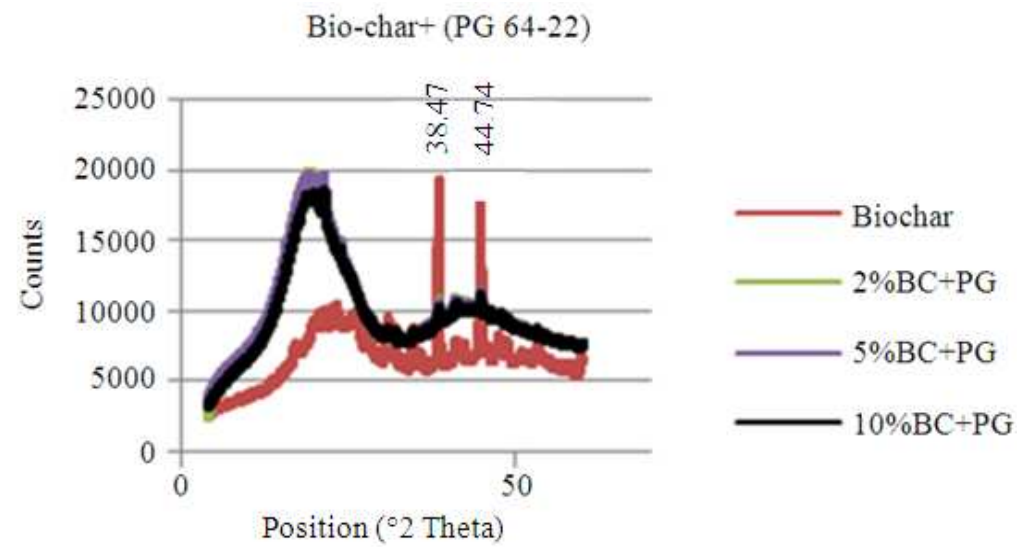

Fig. 6. X-ray Diffraction results of bio-char blended with PG 64-22 at different percentages

Spacing change (increase or decrease) information can be used to determine the level of exfoliation.

$\mathrm{d}=\frac{\lambda}{2 \sin \theta}$

Where:

$\mathrm{d}=$ The inter layer spacing,

$\lambda=1.54 \AA$ and

$\theta=$ The angle at which diffraction peak occurs

For example, no d-spacing change indicates immiscible, an increase in d-spacing indicates intercalation and no distinct peak in the signal indicates exfoliation. In the case of peak in the signal, the dspacing can be determined as shown in Equation 3. This equation was used to determine whether the inter layer spacing of the nano particles increased.

\subsection{Bio-char}

XRD results shown in Fig. 6 were used to analyze samples including raw bio-char (2, 5 and $10 \%$ bio-char). Based on experimental results, 2, 5 and $10 \%$ bio-char and PG 64-22 all have very similar diffraction pattern. According to the X-ray diffraction results it can be concluded that this additive (bio-char) had little to no impact on the layer spacing. If there was a change in layer spacing a strong peak would have appeared between 0-10 degrees 20. Two very strong peaks appear at 38.47 and 44.74 degrees $2 \theta$. These two peaks are from the aluminum sample holder. The peak that occurs at 21.4 degrees $2 \theta$ in all samples that include PG 
64-22 has shifted which suggests a change in spacing between crystals not layers.

\subsection{Nano-Clay}

Figure 7 is a compilation of all samples that include the additive nano-clay. This figure is a general idea of how each sample behaved after modification compared to raw nano-clay. As observed from Fig. 7, the strong peaks that appear in the nano-clay sample all repeat themselves for the most part at different intensities depending on the sample.

Figure 8 highlights two strong peaks that are observed between 0-10 degrees $2 \theta$ for the raw nano-clay sample, which leads us to conclude that they are both related to the nano-clay. The first peak appears at 4.82 degrees $2 \theta$ with a d-spacing of $9.16 \AA$ calculated using Equation 3 and the second peak occurs at 9.67 degrees $2 \theta$ with a d-spacing of $4.58 \AA$.
Figure 9 analyzes samples including PG 64-22 and nano-clay at 2 and $4 \%$ wt. The results show that exfoliation has occurred in both cases. In both of these samples a peak appears at 5.74 and 6.75 degrees $2 \theta$ respectively which falls between the two peaks that are present in the raw nano-clay sample (without presence of asphalt). Based on these results, exfoliation and intercalation has occurred with the addition of nano-clay to asphalt binder (PG 64-22). The very sharp peak that occurs at 4.82 degrees $2 \theta$ from the raw nano-clay does not seem to have much of an impact.

Figure 10 analyzes samples including nano-clay at 2, $4 \%$ wt. and BMB. Two strong peaks are observed between 0-10 degrees $2 \theta$ for the raw nano-clay sample. In the modified mixtures, the first peak appears at 4.8 degrees $2 \theta$ with a d-spacing of $9.16 \AA$ and the second peak occurs at 9.67 degrees $2 \theta$ with a d-spacing of 4.58 Å. Samples including BMB have completely exfoliated due to no peak appearing between 0-10 degrees $2 \theta$.

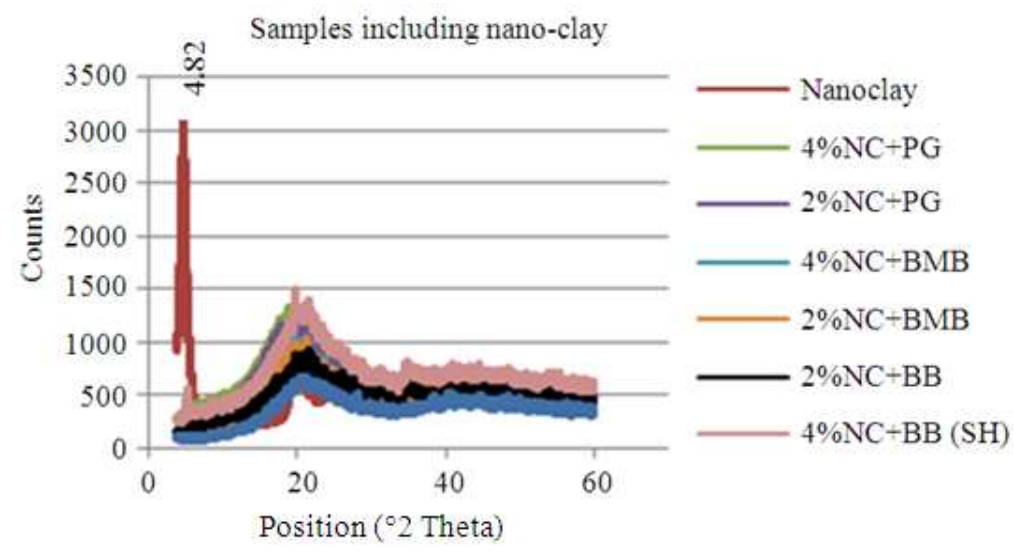

Fig. 7. XRD results of nano-clay blended with PG 64-22 and BMB at different percentages

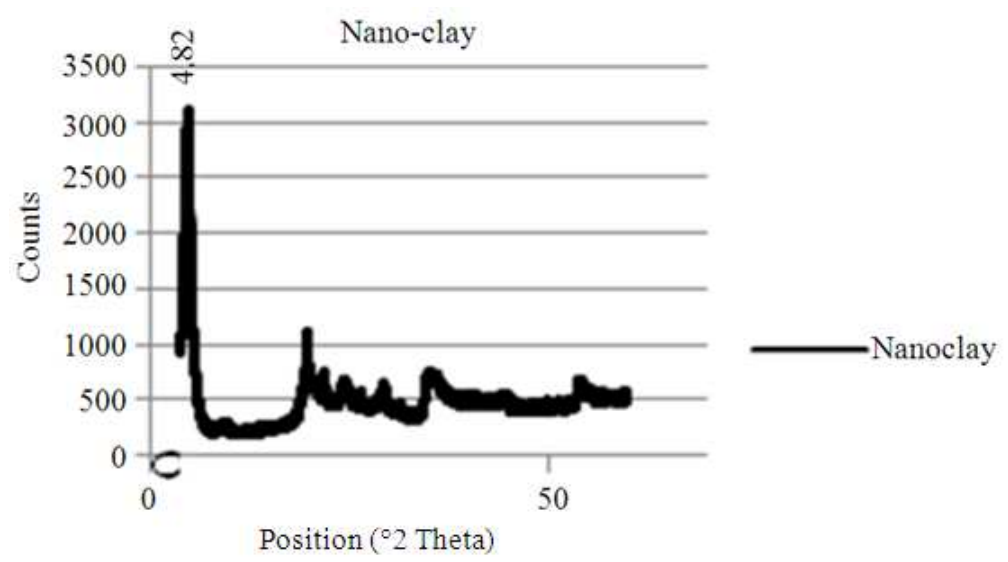

Fig. 8. XRD results of raw nano-clay 


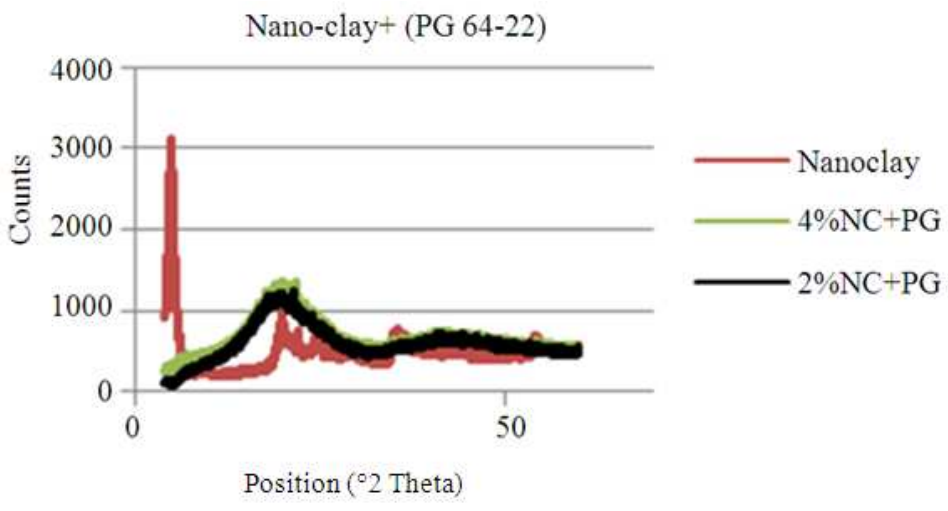

Fig. 9. XRD results of nano-clay blended with PG 64-22 at different percentages

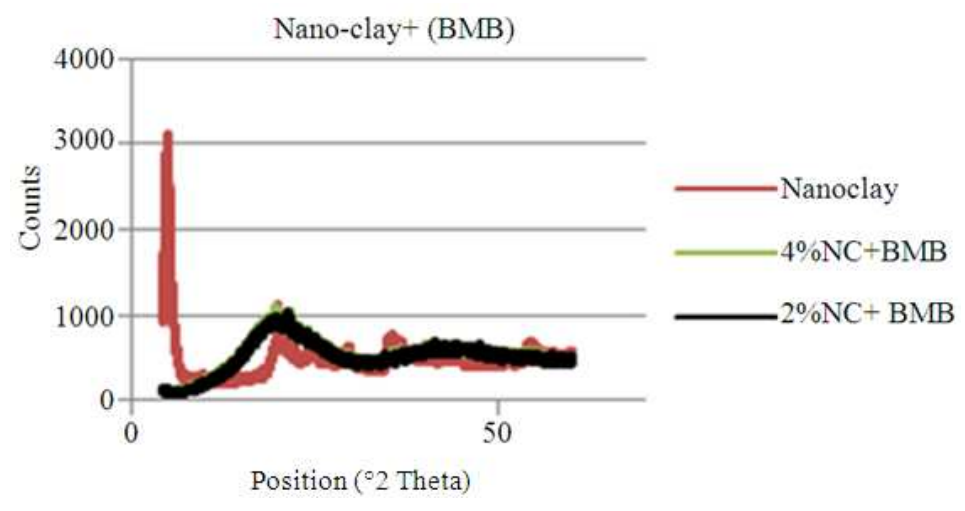

Fig. 10. XRD results of nano-clay blended with $B M B$ at different percentages

\section{DISCUSSION}

Oxidation of asphalt binder is a phenomenon that is inevitable and plays an enormous role in the deterioration of asphalt binder. With that being said, oxidation cannot be completely prevented; however the rate at which asphalt binder oxidizes can be decreased.

To enhance asphalt properties and reduce aging susceptibility in this study bio-char and nano-clay was introduced to the asphalt binder. To investigate the effect of nano-clay and bio-char on asphalt binder properties, two laboratory tests including Rotational Viscosity (RV) test and X-Ray Diffraction (XRD) test were used. These tests were conducted at the Civil Engineering $\mathrm{Lab}$ at North Carolina A\&T State University and at the Centre for Material Science and Engineering at Massachusetts Institute of Technology.

The first test (RV) is used to measure viscosity, which is the rate of deformation due to an applied shear or tensile stress. Analyses were then conducted to determine the temperature susceptibility and shear susceptibility of the samples.

The second test (XRD) is used to determine the crystalline structure of each sample. Crystalline structure causes the incident ray to diffract in various directions. The angle and intensities of the diffracted rays are then measured. Based on these factors a pattern was produced. The incident ray angle range was between 4-60 degrees. Each sample was tested for two hours. The peaks formed based on the crystalline structure of each sample, were then analyzed and the inter layer spacing was calculated.

\section{CONCLUSION}

This study investigates the effects that nano clay and bio-char particles have on the rheological characteristics and aging susceptibility asphalt binder with and without bio-binder. Based on the test results for nano particlemodified asphalt and bio-modified asphalt nanocomposites, the following conclusions can be made: 
- The viscosity increased with the addition of nanoparticles into control asphalt binder (PG 64-22)

- Introduction of bio-char to asphalt binder leads to reduction of asphalt temperature susceptibility

- The viscosity of the bio-modified binder with nanoclay was found to be significantly higher than biomodified binder without nano-clay

- The overall shear susceptibility reduces significantly when 10\% bio-char mixed with PG 64-22

- Shear susceptibility for $10 \%$ bio-char mixed with PG 64-22 is consistently lower than control asphalt

- X-ray diffraction results for bio-char samples show that this additive (bio-char) had little to no impact on the layer spacing

- X-ray diffraction results for nano-clay modified samples show that intercalation and exfoliation occurred in all cases as evidenced by the peaks of nano-clay modified samples falling between the two peaks associated with raw nano-clay. This in turn suggests the increase of layer spacing due to the modification

In summary, the addition of nano-particles to control and bio-modified asphalt binder found to be effective to enhance the high temperature performance and aging resistance of the asphalt binders. This was mainly attributed to the change of layer spacing in nano-clay as observed by XRD results.

\section{REFERENCES}

Amirkhanian, A.N., F. Xiao and S.N. Amirkanian, 2010. Evaluation of high temperature rheological characteristics of asphalt binder with carbon nano particles. J. Testing Evaluation, 39: 0090-3973.

ASTM, 2013. Products and Services, Standards and Publications, Standard Products.

CDT, 2013. Selection of Asphalt Binder Grade. California Department of Transportation.

Claudy, P.M. and D. Martin, 1998. Thermal behavior of asphalt cements. Thermochemica Acta, 324: 203-213. DOI: 10.1016/S0040-6031(98)00537-1

Fini, E.H., E.W. Kalberer, A. Shahbazi, M. Basti and Z. You et al., 2011b. Chemical characterization of biobinder from swine manure: Sustainable modifier for asphalt binder. J. Materials Civil Eng., 23: 1506-1513. DOI: 10.1061/(ASCE)MT.1943-5533.0000237
Fini, E.H., I.L. Al-Qadi, Z. You, B. Zada and J. MillsBeale, 2011a. Partial replacement of asphalt binder with bio-binder: Characterization and modification. Int. J. Pavement Eng., 13: 515-522. DOI: 10.1080/10298436.2011.596937

Firoozifar, S. and S. Foroutan, 2011. The effect of asphaltene on thermal properties of bitumen. Chem. Eng. Res. Design 89: 2044-2048. DOI: 10.1016/j.cherd.2011.01.025

Goh, S.W., M. Akin, Z. You and X. Shi, 2011. Effect of de-icing solutions on the tensile strength of microor-nano-modified asphalt mixture. Construct. Build. Materials, 25: 195-200. DOI: 10.1016/j.conbuildmat.2010.06.038

Jarecki, M.K., T.B. Parkin, A.S. Chan, J.L. Hatfield and R. Jones, 2008. Greenhouse gas emissions from two soils receiving nitrogen fertilizer and swine manure slurry. J. Environ. Q., 37: 1432-1438. DOI: 10.2134/jeq2007.0427

Lee, L.J., C. Zeng, X. Cao, X. Han and J. Shen et al., 2005. Polymer nanocomposite foams. Composites Sci. Technol., 65: 2344-2363. DOI: 10.1016/j.compscitech.2005.06.016

Lehmann, J., 2007. Bio-energy in the black. Frontiers Ecol. Environ., 5: 381-387. DOI: 10.1890/15409295(2007)5[381:BITB]2.0.CO;2

MacDonald, J. M., McBride, W. D. (2009). The Transformation of U.S. livestock agriculture: scale, efficiency and risks, U.S. Dept. of Agriculture, Economic Research Service EIB-43, Washington DC.

McHenry, M.P., 2009. Agricultural bio-char production, renewable energy generation and farm carbon sequestration in Western Australia: Certainty, uncertainty and risk. Agriculture, Ecosyst. Environ., 129: 1-7. DOI: 10.1016/j.agee.2008.08.006

Mullen, C.A., A.A. Boateng, N.M. Goldberg, I.M. Limw and D.A. Laird et al., 2010. Bio-oil and bio-char production from corn cobs and stover by fast pyrolysis. Biomass Bioenergy, 34: 67-74. DOI: 10.1016/j.biombioe.2009.09.012

Ocfemia, K.S., Y. Zhang and T. Funk, 2005. Hydrothermal process of swine manure to oil using a continuous reactor system: Development and testing. Am. Soc. Agric. Biol. Eng., 49: 533-541.

Rasmussen, R., R.L. Lytton and G.K. Chang, 2002. Method to predict temperature susceptibility of an asphalt binder. J. Materials Civil Eng., 14: 246-252. DOI: 10.1061/(ASCE)0899-1561(2002)14:3(246) 
Roberts, F.L., Kandhal P. S., Brown E. R., Lee D. Y., Kennedy T. W., (1996). Hot Mix Asphalt

Materials, Mixture, Design and Construction, in National Asphalt Pavement Association

Research and Education Foundation, Lanham, Md.

Rubio, M.C., G. Martinez, L. Baena and F. Moreno, 2012. Warm mix asphalt: An overview. J. Cleaner Production, 24: 76-84. DOI: 10.1016/j.jclepro.2011.11.053

Thu, K., K. Donham, R. Ziegenhom, S. Reynolds and P.S. Thorne et al., 1997. A control study of the physical and mental health of residents living near a large-scale swine operation. J. Agric. Safety Health, 3: 13-26. DOI: $10.13031 / 2013.17747$
Xiu, S.N., H.K. Rojanala, A. Shabazi, E.H. Fini and L. Wang, 2011. Pyrolysis and combustion characteristics of bio-oil from swine manure. J. Thermal Analysis Calorim., 107: 823-829. DOI: 10.1007/s10973-011-1604-8

You, C.H., B.G. Kim, J.M. Kim, S.D. Yu and Y.M. Kim et al., 2011. Relationship between blood mercury concentration and waist-to-hip ratio in elderly Korean individuals living in coastal areas. J. Prev. Med. Public Health, 44: 218-25. DOI: 10.3961/jpmph.2011.44.5.218, PMID: 22020187 